\title{
Randomized clinical trial of an intensive nursing-based pain education program for cancer outpatients suffering from pain
}

\author{
Evelien H. van der Peet • \\ Marieke H. J. van den Beuken-van Everdingen • \\ Jacob Patijn • Harry C. Schouten • Maarten van Kleef • \\ Annemie M. Courtens
}

Received: 28 July 2008 / Accepted: 9 December 2008 / Published online: 23 December 2008

(C) The Author(s) 2008. This article is published with open access at Springerlink.com

\begin{abstract}
Introduction The prevalence of pain in patients with cancer is still too high. Factors relating to ineffective pain treatment fall into three categories: the health care system, professional care providers, and patients. In patients, various barriers lead to noncompliance. Previous educational interventions have increased their knowledge of pain and decreased short-term pain levels. In this randomized controlled trial, the authors investigated how an intensive home-based education program given by nurses affected short-term and long-term pain levels.

Materials and methods One hundred and twenty cancer patients were randomized to receive either the pain education program (PEP) or usual care. Pain, knowledge, quality of life, anxiety, and depression were measured at
\end{abstract}

E. H. van der Peet

Comprehensive Cancer Center Limburg,

Maastricht, The Netherlands

M. H. J. van den Beuken-van Everdingen $(\bowtie) \cdot J$. Patijn

Department of Anesthesiology, Pain Management and Research

Centre, University Hospital Maastricht,

P.O. Box 5800, 6202 AZ Maastricht, The Netherlands

e-mail: m.vanden.beuken@mumc.nl

H. C. Schouten

Department of Internal Medicine, University Hospital Maastricht, Maastricht, The Netherlands

M. van Kleef

Department of Anesthesiology, University Hospital Maastricht, Maastricht, The Netherlands

A. M. Courtens

Department of Transmural Care, University Hospital Maastricht, Maastricht, The Netherlands baseline and after 4 and 8 weeks. In the intervention group, effects on symptom levels were communicated to the treating physician.

Results The level of pain had decreased at 4 weeks, but not at 8 weeks. Significant decreases in pain only persisted in those patients with a high pain score at baseline. Knowledge of pain significantly increased in the intervention group. No correlation was found between increased pain knowledge and decreased pain levels.

Conclusions The PEP given by nurses lowered pain intensity levels in cancer patients and increased their knowledge of pain. More attention should be paid to patient education and to communication between patients and health professionals regarding pain and pain management.

Keywords Randomized clinical trial · Pain education program $\cdot$ Cancer outpatients $\cdot$ Pain $\cdot$ Pain management

\section{Introduction}

Many cancer patients have (multiple) symptoms that can affect their feeling of well-being as well as their physical and social functioning. One of the most feared and burdensome physical symptom in cancer patients is pain. A recent review has shown that the prevalence of pain in cancer patients is still high: $64 \%$ in patients with metastatic, advanced, or terminal disease and $59 \%$ in patients on anticancer treatment [1].

Factors relating to ineffective pain management fall into three categories: the health care system, health care providers, and patients [2]. In the health care system, more attention is focused on "curing" cancer patients than on 
"caring" for them; this includes symptom management [3]. Health care providers tend to show a lack attention for and knowledge about pain management [4-11] and, as a consequence, do not always treat pain according the World Health Organization guidelines $[5,10]$. Patients generally lack knowledge about pain and pain management and are reluctant to report pain to their physician [11, 12]. Fears such as drug addiction, tolerance, and concerns about side effects also influence their intake of pain medication [6,1316]. However, patients indicated that they would appreciate help with their physical and psychosocial problems and would like to receive information on this [17-19].

In the health care provider category, Goldberg and Morison conducted a systematic review of institutional interventions designed to improve the assessment and treatment of pain in cancer patients [20]. This review included three trials that studied the effects of education for nurses on pain-related topics [21-23]. They concluded that these education sessions improved nurses' knowledge of pain and their attitudes toward it [20]. However, these interventions did not lead to any significant decrease in the severity of pain in their patients [20]. None of the randomized controlled trials (RCTs) specifically targeted other health care providers or physicians.

In the present study, we focused on patient-related factors in the knowledge and management of pain. A review of 17 RCTs on pain and pain management education for patients [24-40] suggested that tailored education counseling sessions directed at patients improved pain scores [24-26, 29-31, 33, 34, 37, 38, 40] and altered any negative beliefs and misconceptions about pain $[25,26,29$, $30,32,33,37,39]$. In 12 studies, pain education was provided by nurses [24, 25, 27-29, 31-33, 35-37, 39]; in two studies, pain education was provided by other health care educators (e.g., research assistants, master students) $[26,30]$; in two other studies, this aspect was not mentioned [34, 38]; and in the final study, a video was shown [40]. Although the results of the patient-related RCTs were generally positive, there is still a need to gain more insight into the efficacy of pain education programs (PEPs) [31]. There were methodological flaws in many areas in existing RCTs. In most studies, only the short-term effects were measured $[25,26,28-31,34,38,40]$. It is not clear whether short-term effects are sustained over longer periods of time. The education programs were generally fairly light (e.g., one face-to-face education session or one session combined with one or more telephone calls) [24-26, 32-35, 37-40], while it is well-known that patients and their family care providers require ongoing assistance with problem-solving in order to optimize their pain management regimen [41]. Little is known about which subgroups gain the most from PEPs. This knowledge is necessary in order to tailor education programs and to maximize their effectiveness
[42]. Only one study indicated that the educational level of patients might influence the effects of PEPs [43]. Only a very small proportion of the studies incorporated variables such as gender, age, and stage of the disease [32, 33]. None of the studies mentioned incorporated pain scores at baseline or anxiety and depression scores at baseline, although depression and pain form a well-known cluster [44] and depressive disorders can affect compliance [45]. The study population was small in almost half the RCTs with less than 35 participants in the intervention and control groups $[26,29,30,34-36,40]$. Attention was paid to communication between the nurses who gave the education and the treating physicians in only one study [25], although continuity of care and communication between health care providers is known to be of major importance in the pain management process [43].

In the present study, we tried to avoid making any of the above-mentioned methodological errors. Our aim was to evaluate how an intensive home-based PEP given by nurses affected the short-term and long-term effects of levels of pain, pain knowledge, quality of life, anxiety, and depression.

\section{Materials and methods}

\section{Source population}

Patients were recruited from two sources: Firstly, from our previous prevalence study on pain and other symptoms in the province of Limburg, situated in the south of The Netherlands. The outpatients who scored 4 or higher on the pain intensity scale (range $0-10,10=$ worst pain) and who gave their written consent to participate in the next research project were asked to participate in this intervention study. This resulted in 54 patients. Secondly, patients were recruited by nurses and physicians working at outpatient clinics and the radiotherapy department. This resulted in 65 patients. A total 120 patients were included.

Patients were eligible if (1) they had been diagnosed with cancer, (2) they had been informed of their diagnosis, (3) they were aged 18 years or more, (4) they were able to understand and complete the questionnaire, (5) they had a "present" pain score of 4 or higher on a scale of from 0 to 10 , and (6) they had agreed to participate in the study. Treatment stages included curative anticancer treatment, palliative anticancer treatment, and no further treatment options available. Patients were excluded if they had completed their curative anticancer treatment before the year 2000 .

The study was approved by the Medical Ethics Committee of the University Hospital Maastricht. All the participants gave written informed consent. 


\section{Intervention}

All patients were randomly allocated to the intervention group $(n=58)$ or the control group $(n=62)$, based on a computer-generated randomization procedure.

Patients in the control group received their usual care from their treating physician. Patients in the intervention group received specialized nursing care at home, at the same time as the care received from their treating physician (Fig. 1). This specialized care included the PEP and the monitoring of symptoms other than pain.

The PEP was developed by De Wit et al. [37] and consists of the following three components: (1) enhancement of patients' pain knowledge and pain management by means of a brochure, (2) instruction of patients as to how they should record their pain intensity in a pain diary, and (3) stimulation of patients' help-seeking behavior. An extensive description of the PEP can be found in the article in which it originally appeared [37]. In the intervention group, palliative care nurses made three home visits, each lasting $1-1.5 \mathrm{~h}$.

The pain brochure provides information on the following topics: possible causes of pain, pain control, nonadherence, misconceptions, and various nonpharmacological pain management techniques (cold, heat, relaxation, and massage). This brochure was tested in an earlier study [46].

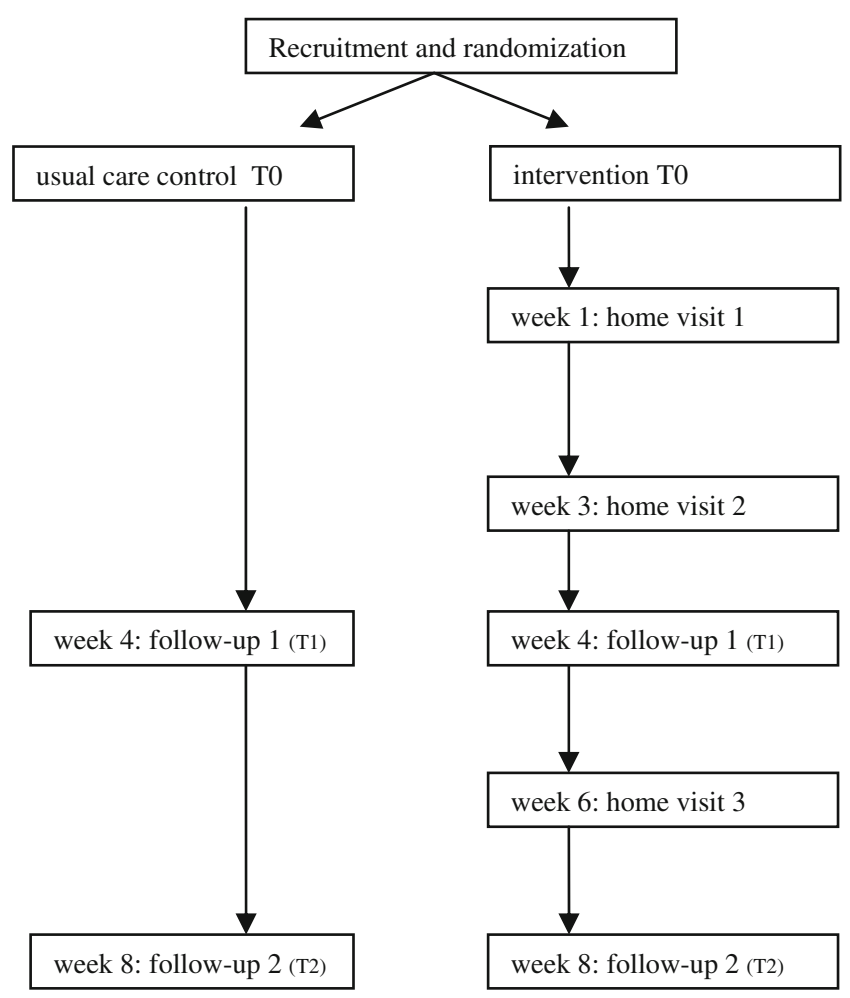

Fig. 1 Study design

\section{First home visit}

The first home visit took place within 1 week of the baseline measurement. Intake data were recorded by the nurses in order to tailor the PEP to the patient's situation. These data were connected with intensity of pain, location of pain, type of pain, prescription of medication, adherence to medication, emotional well-being, and other physical symptoms. A pain brochure was handed to the patient and, if possible, studied in the presence of a family caregiver. Patients were invited to ask questions. They also received a pain diary with a clear explanation on how to record their pain intensity twice daily using a numerical rating scale from 0 to 10 . If any pain problems or other physical and emotional symptoms arose, patients were encouraged to contact their health care provider.

After the first visit, the nurses reported their findings to the treating physician in writing. If necessary, advice was given with regard to pain medication, in all cases in consultation with a specialist in the pain treatment of oncology patients. This advice consisted of starting new pain medication, increasing the dosage of pain medication, or changing to a different pain medication regimen and was enclosed with their report.

\section{Second home visit}

During the second home visit, which took place in week 3, the nurse reviewed the pain intensity scores in the pain diary in order to detect any changes in pain intensity levels. Any changes in type of pain, location of pain, prescription of pain medication, or adherence to medication were also reviewed. Patients were asked whether they had read the "pain brochure" themselves and had fully understood all the information. Care was taken to discuss anything that was unclear to them in the brochure and/or to repeat relevant information. If necessary, patients were encouraged to contact their health care provider regarding their pain problems and/or other symptoms.

\section{Third home visit}

The third and final home visit, which took place in week 6, dealt with the same points as the second visit. Thereafter, the nurse wrote to the treating physician regarding the patient's situation. If necessary, advice was given in connection with a change in pain medication and enclosed with the report.

\section{Measurements}

Outcome measurements were assessed in both the intervention and control groups at baseline (T0), week 4 (T1), and week 8 (T2) (Table 1). 
Table 1 Study measurements at T0 (baseline), T1 (week 4), and T2 (week 8)

\begin{tabular}{lccc}
\hline Outcome measures & T0 & T1 & T2 \\
\hline Pain intensity & + & + & + \\
Pain knowledge & + & & + \\
Quality of life & + & + & + \\
Anxiety and depression & + & & + \\
Process variables (intervention group only) & & & \\
Patient satisfaction & & & + \\
Use of pain diary & & & + \\
Use of CD & & & + \\
Use of information booklet & & & + \\
Medication prescription & + & + & + \\
\hline
\end{tabular}

Relevant medical data and information on other interventions that targeted pain and other symptoms were obtained from the medical records. Pain was measured using four questions taken from the Brief Pain Inventory (numerical rating scale) [47]. This has high internal consistency with coefficient alphas ranging from 0.78 to 0.97 in various cancer population samples from different countries [48-57]. The "present" pain score was chosen as a primary outcome, since it is less subject to the biases that affect recall measurements [58], and patient recall accuracy depends, in part, on the stability of the pain [43].

Patients' knowledge about pain was measured with a translated version of Ferrell's Pain Questionnaire [59, 60]. The questionnaire consists of eight items, including patients are often given too much pain medication, most patients become addicted to their medication over time, and it is better to take pain medication around the clock (following a schedule) than only when needed. All the scores were converted linearly into a scale of from 0 to $100(0=$ lowest knowledge score, $100=$ highest knowledge score). PKQDLV has demonstrated acceptable levels of validity and reliability [43].

Quality of life and nonpain symptoms were measured using EORTC-C30 version 3 [61]. EORTC-C30 is (1) cancer-specific, (2) multidimensional, (3) suitable for selfadministration, and (4) applicable across a range of cultural settings. It consists of five functional scales, three symptom scales, a global health/quality of life scale, and six single items. EORTC QLQ-C30 has shown acceptable levels of validity and reliability [61].

Depression and anxiety were measured using the Dutch version of the Hospital Anxiety and Depression Scale (HADS) [62]. HADS performs well when assessing symptom severity and caseness of anxiety disorders (Cronbach's $\alpha=0.68-0.93$ ) and depression (Cronbach's $\alpha=0.67-0.90)$ in somatic, psychiatric, and primary care patients with a sensitivity and specificity of approximately 0.80 [63].
Participation satisfaction with the intervention was measured by asking patients the following questions: (1) Would you like to continue following the PEP? (2) Would you advise other patients to take part in the PEP? Response options were "yes" or "no."

Use of materials was evaluated at the end of the study by asking patients whether they had used the pain diary and the compact disc (CD) and read the information booklet. Response options were "yes" or "no."

Advice regarding a change in pain medication prescription at T0, T1, and T2 was analyzed by comparing the advice in the reports to the treating physician to the patients' reports about pain medication.

\section{Statistics}

A total of 80 patients were needed in order to ensure that the main effects of the treatment group on pain intensity could be tested adequately. Many patients would not able to complete the study, either because they would become too ill or would die. Therefore, 120 patients were recruited to ensure that 80 would complete the study. The power analysis conducted in this study was based on data from an earlier study of the PEP [43]. It was necessary to have 40 patients in both the intervention and control groups in order to obtain a clinically relevant difference of 1.5 points on a ten-point scale with an alpha of 0.05 , a beta of 0.20 , and a standard deviation (SD) of 2.4. Data were analyzed using the Statistical Package for the Social Science version 12. Descriptive statistics were used to evaluate the demographic variables, medical variables, pain, symptoms other than pain, knowledge about pain and pain treatment, quality of life, depression, and anxiety. At T0, comparability between the intervention and control groups was analyzed using independent Student's $t$ tests and chi-square tests.

Mixed regression models were used to evaluate the longitudinal data on the effects of PEP and changes over time. The high number of patients not completing this study, mainly due to severe illness and death, led to an unbalanced data set that could not be analyzed using traditional methods, such as repeated-measures analysis of variance. Mixed regression models offering an alternative for dealing with unbalanced data sets can be found in the literature [64]. Therefore, the changes in outcome measures and pain over time were tested using the random intercept model.

\section{Results}

A total of 120 patients were entered in the study (Fig. 2). At T2, 83 of these patients had completed the follow-up. After randomization, 13 patients were excluded (eight from the 


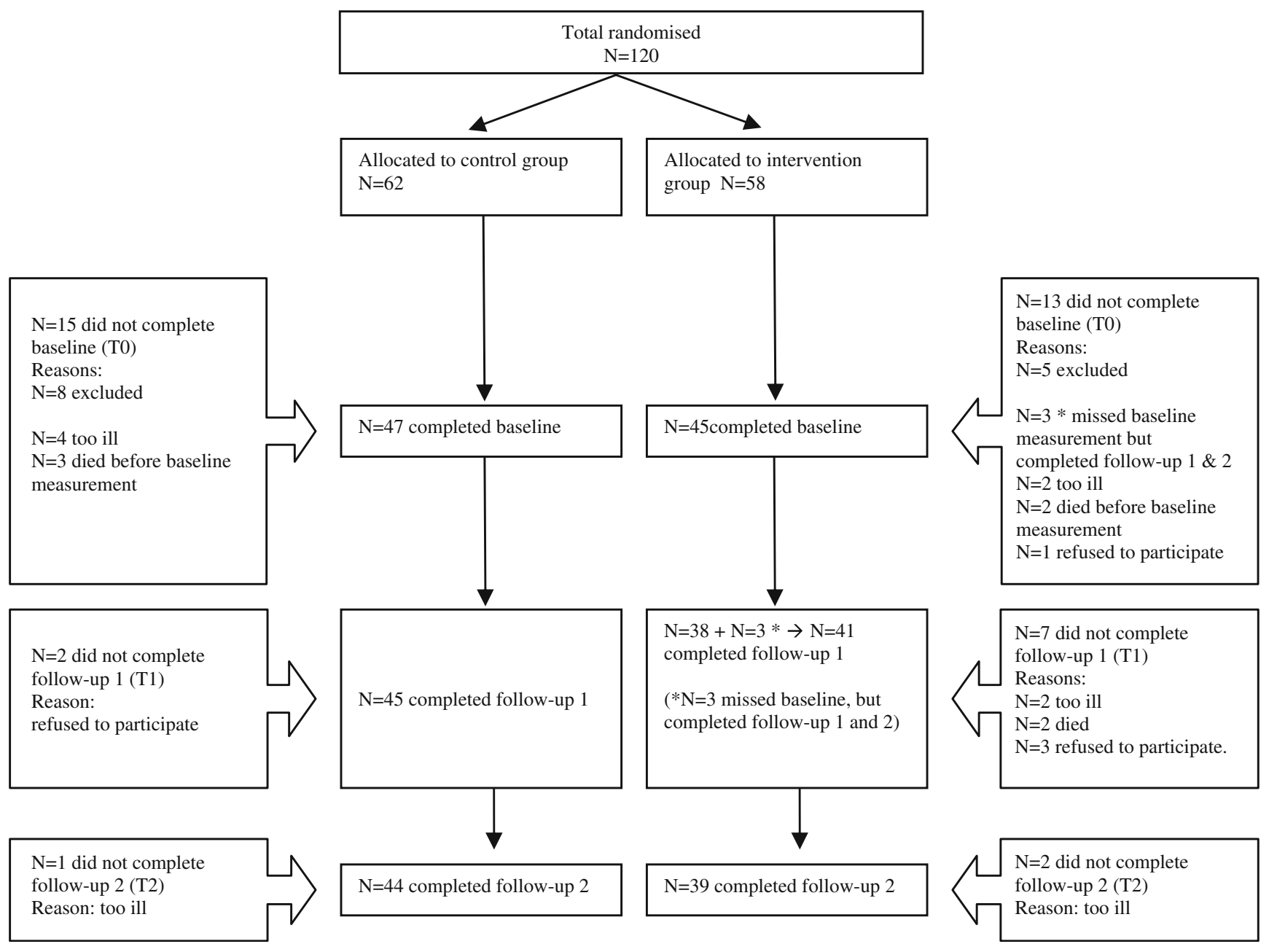

Fig. 2 Flowchart of participants

control group, five from the intervention group) because they did not meet the inclusion criteria: seven patients were not suffering from cancer-related pain (arthritis, three cases; osteoporosis, one case; rheumatic disease, one case; dialysis, one case; and carpal tunnel syndrome, one case), four patients had completed their curative treatment before 2000 , and one was already familiar with the PEP brochure. Data were missing at baseline, T1, or T2 in 27 patients (ten in the control group, 17 in the intervention group) (for further details, see Fig. 2).

No significant differences were found in the demographic characteristics, treatment group, and baseline pain levels between the intervention and control groups at baseline (Table 2). Despite the randomization procedure, the baseline level of pain knowledge was significantly better in the control group than in the intervention group ( $p=$ 0.017). The lowest scores at baseline were observed for the item "take the lowest dose of medication possible" in both the intervention and control groups (16.9 and 27.7, respectively). No significant differences were found in the categories quality of life (except for role functioning) or prevalence of other symptoms.

Changes in the level of pain, level of pain knowledge, quality of life, anxiety, and depression

On short-term measurement (week 4), the intervention group showed significant pain reduction $(p=0.02)$ compared to the control group (Fig. 3a). No significant ( $p=$ 0.14 ) long-term effect was seen (Table 3 ).

The level of pain knowledge was measured at baseline (T0) and after 8 weeks (T2). At week 8, the level of pain knowledge was significantly better in the intervention group $(p<0.00)$ than in the control group (Fig. 3b). Significant improvement was seen for the items "take the lowest dose of medication possible", "use of routine 
Table 2 Baseline characteristics in the intervention group and the control group

\begin{tabular}{|c|c|c|c|}
\hline & Intervention group & Control group & $p$ value \\
\hline \multicolumn{4}{|l|}{ Age (years) } \\
\hline Mean (SD) & $62.0(10.3)$ & $60.5(10.0)$ & NS \\
\hline \multicolumn{4}{|l|}{ Gender $(\%)$} \\
\hline Men & 52.1 & 38.3 & NS \\
\hline Women & 47.9 & 61.7 & NS \\
\hline \multicolumn{4}{|l|}{ Education (\%) } \\
\hline Primary school & 77.1 & 70.2 & NS \\
\hline Secondary school & 6.3 & 4.3 & NS \\
\hline College/university & 10.4 & 23.4 & NS \\
\hline Missing & 6.3 & 2.1 & NS \\
\hline \multicolumn{4}{|l|}{ Treatment group (\%) } \\
\hline Group 1 & 20.8 & 27.7 & NS \\
\hline Group 2 & 58.3 & 53.2 & NS \\
\hline Group 3 & 18.8 & 17.0 & NS \\
\hline Missing & 2.1 & 2.1 & NS \\
\hline Baseline pain ${ }^{a}$ & 4.43 & 4.71 & NS \\
\hline Pain knowledge & 52.8 & 59.5 & 0.017 \\
\hline
\end{tabular}

Group 1 patient is currently under curative anticancer treatment or this treatment has finished ( $<5$ years), Group 2 patient is currently under palliative anticancer treatment or this is a treatment option, Group 3 no further treatment options available

${ }^{\mathrm{a}}$ Present pain

medication instead of on demand" and "becoming addicted" in the intervention group. Levels of pain knowledge did not improve in the control group (Table 4).

No correlation was found between the increase in pain knowledge and the change in "present" pain scores (Pearson correlation $=0.03, p=0.860$ ). Quality of life did not show any significant effects over time.

Factors relating to short-term and long-term changes in pain scores

The "present" pain intensity at baseline had a significant influence on the "present" pain intensity on short-term and long-term measurement (Fig. 4). There were no differences in pain scores at T1 (week 4) and T2 (week 8) between the intervention and control groups in patients with a baseline pain score of 1-3. At T1, pain was significantly lower in the intervention than in the control group $(p=0.02)$ in patients with a baseline pain score of 4-6. However, this difference had disappeared at T2 $(p=0.13)$. Significant differences in pain were found between the intervention and control groups at T1 $(p=0.00)$ and T2 $(p=0.00)$ in patients with a baseline score of 7-10.

Neither gender, age, education level, severity of illness, nor baseline levels of anxiety and depression had a significant influence on the "present" pain intensity levels in either the intervention or the control group.
Adherence to advice about medication from treating physicians

After the first and third home visits, the nurse reported in writing to the treating physician regarding the patient's pain problems (intensity, location, and type). In 37 cases, this report included advice in connection with a change in the pain medication regimen. In 22 of these cases, this advice was ignored. In eight cases, it was unclear whether this advice had been taken or not.

Patient opinion regarding the pain education program

When patients with complete data sets (29 cases) were asked whether they would like to continue with the PEP,
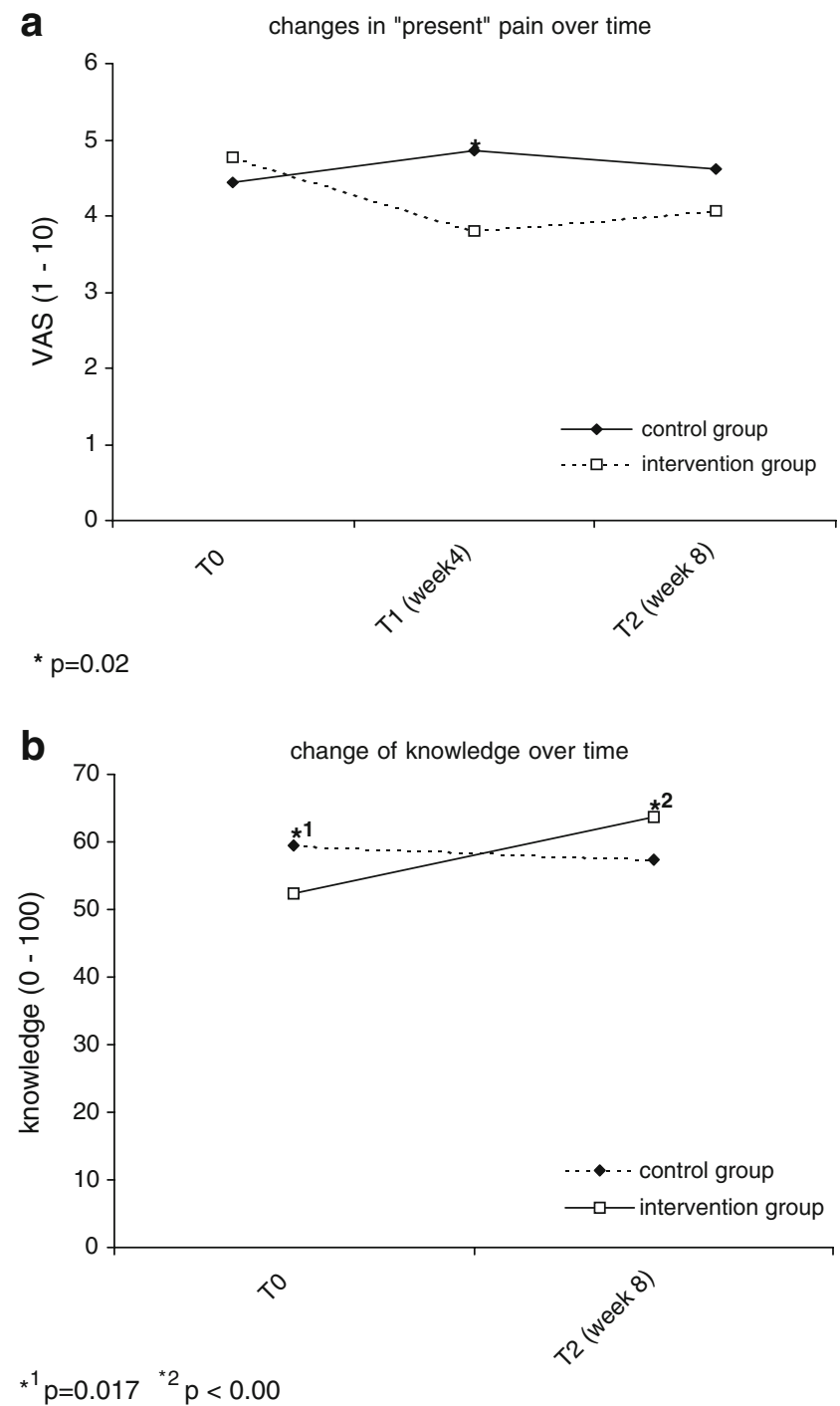

Fig. 3 Changes in the level of pain and the level of pain knowledge in the intervention and the control group over time. a Changes in "present" pain over time. $* p=0.02$. b Change of knowledge over time. ${ }^{* 1} p=0.017 ; *^{2} p<0.00$ 
Table 3 Mean "present" pain scores in the intervention group and the control group at baseline (T0), week 4 (T1), and week 8 (T2)

\begin{tabular}{lccc}
\hline & \multicolumn{2}{l}{ "Present" pain } & $p$ value \\
\cline { 2 - 3 } & $\begin{array}{l}\text { Intervention group } \\
\text { Mean (SD) }\end{array}$ & $\begin{array}{l}\text { Control group } \\
\text { Mean (SD) }\end{array}$ & \\
\hline T0 & $4.71(2.21)$ & $4.43(2.33)$ & 0.72 \\
T1 (week 4) & $3.78(2.63)$ & $4.84(2.62)$ & 0.02 \\
T2 (week 8) & $4.00(2.17)$ & $4.62(2.25)$ & 0.14 \\
\hline
\end{tabular}

$66 \%$ replied that they would like to continue to receive support from the specialized nurse. The most important reasons for this were support and having someone available to answer questions on pain medication. The patients who did not wish continue reported that the three sessions had been enough for them to be able to follow the information on pain and pain medication. When asked whether they would advise other patients with pain complaints to take part in the PEP, all patients replied that they would. Patients' response to the third question in the pain brochure, the pain diary, and the educational CD revealed that $73 \%$ had read the pain brochure and used the pain diary.

\section{Discussion}

In this RCT, an intensive pain intervention program presented by nurses resulted in short-term pain reduction in patients with moderate pain at baseline and in long-term pain reduction in patients with severe pain at baseline. The intervention improved patients' knowledge of pain and pain medication. Furthermore, patients were satisfied with the intervention and would recommend it to others.

In most RCTs on educational interventions in patients, pain reduction was noted in the short-term (1 to 4 weeks) [24-26, 29, 30, 33, 34, 37, 38, 40]. These interventions differed greatly in type and intensity, ranging from showing a video [40], having a single face-to-face meeting [25, 26,

Table 4 Mean scores on level of pain knowledge in the intervention group and control group at baseline (T0) and week 8 (T2)

\begin{tabular}{llll}
\hline & \multicolumn{2}{l}{ Level of Pain Knowledge } & $p$ value \\
\cline { 2 - 3 } & $\begin{array}{l}\text { Intervention group } \\
\text { Mean (SD) }\end{array}$ & $\begin{array}{l}\text { Control group } \\
\text { Mean (SD) }\end{array}$ & \\
\hline TO & $52.85(12.96)$ & $59.51(13.64)$ & 0.017 \\
T2 (week 8) & $63.30(13.10)$ & $57.05(15.39)$ & $<0.00$ \\
\hline
\end{tabular}

a changes in "present" pain over time in subgroups according to baseline pain in the intervention group

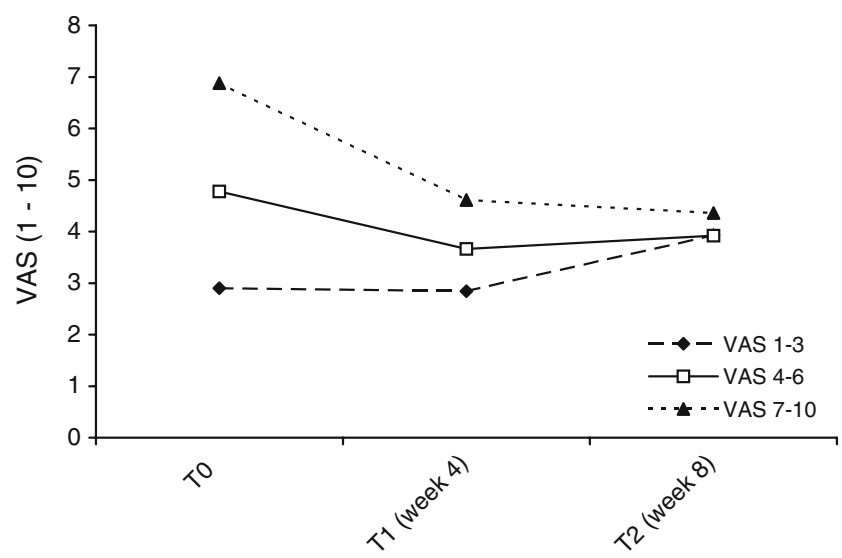

b changes in "present" pain overtime in subgroups according to baseline pain in the control group

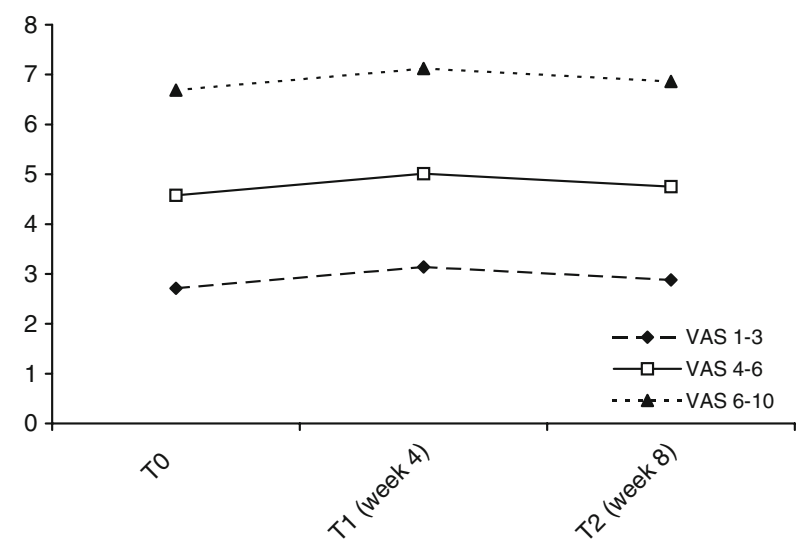

Fig. 4 Changes in "present" pain over time in three subgroups according to baseline pain (mild, moderate, and severe baseline pain). a Changes in "present" pain over time in subgroups according to baseline pain in the intervention group. b Changes in "present" pain overtime in subgroups according to baseline in the control group

$34,38]$, setting up a combination of one to three face-toface meetings and one or more telephone consultations [24, $30,33,36]$, to conducting five face-to-face meetings over 5 days [29]. However, not all the results of the short-term studies were positive [28, 31, 35, 39].

Far fewer studies focused on the long-term effects. The majority did not see any long-term (6 weeks to 6 months) effects on pain intensity $[24,33,35,36,39]$. However, one study showed improvement [27] and two reported longterm pain reduction $[31,37]$. The interventions used also differed widely in type and intensity.

The intensity of an intervention is apparently not the only effective component of a PEP, since neither the type nor the intensity could predict a positive outcome. In our study, patients with more severe pain at baseline (visual analog scale [VAS] scores of 7-10) achieved most benefit 
from the intervention, in both the short-term and long-term. In neither the intervention nor the control group did we find that gender, age, education level, severity of illness, or baseline levels of anxiety and depression significantly influenced the "present" pain intensity levels. None of the other articles studied were suitable for comparison purposes. Only one study mentioned that demographic parameters did not greatly affect the impact of the intervention, but it was unclear what these authors, in fact, meant [32]. Another study classified the population according to race and found a positive short-term effect in African Americans, but not in Hispanics [24].

Apart from better patient selection, other possible factors for improving the long-term effectiveness of an intervention are (1) the close involvement of family caregivers in the education program $[31,37]$ and (2) direct feedback from the nurse to the treating physician on pain levels and other problems. Aubin's study [25] was the only other one in which the nurses directly communicated the results of the intervention to the patient's treating physician. However, it was unclear how they reported the results to the treating physicians and whether this had any effect. In our study, the specialized nurses wrote to the treating physicians with details of the patients' pain levels, other symptoms, and further observations. If a patient had rated their pain as VAS $>4$, the report also advised the physician to change the pain medication regimen. The contents of the advice were formulated in cooperation with a physician from the palliative care team and according to the Dutch guidelines for pain management [65]. We observed that much of the advice was not followed, suggesting that this means of communication was inadequate. Possible explanations could be that the report was stored unread in the patient's medical file, too much time had elapsed between receiving the report and actual patient-physician contact, or reluctance from the physicians to follow uninvited advice. Another explanation could be insufficient involvement of the treating physicians in the implementation of the intervention. Future comparable research projects might benefit from closer communication with the treating physician. Support for this argument can be found in the study by Vallieres [34]. Direct access to a physician who could adjust the analgesic regimen formed part of the intervention. Patients were clearly instructed when (at what pain level, or after three rescue doses in $24 \mathrm{~h}$ ) to contact their doctor. In addition, they were asked to bring their pain diary with them to the consultation, to help the doctor adjust the analgesic regimen, and also to improve communication between the patient and the doctor. Although the study sample was small, the results seem to be promising. Unfortunately, no long-term effects have been reported [34]. In all the above-mentioned RCTs, part of the education program was to encourage patients to talk to their treating physician about their pain. However, no data are available on the effects of patient education on communication with treating physicians.

In agreement with most of the other RCTs, our study showed an increase in pain knowledge following the intervention. In one trial, only the informal caregiver improved his knowledge [36], whereas in two trials, there was no effect on pain knowledge [35, 39]. The rationale behind PEPs for patients is based on the presumption that better-educated patients will adhere better to their medication regimen and communicate more adequately with their treating physician. In our study, no correlation was found between an increase in pain knowledge and a decrease in pain level. In the field of cardiology, it was shown that patient education led to significantly lower levels of lowdensity lipoprotein cholesterol in high-risk patients $(n=$ $3,053)[66]$ and to significantly fewer admissions for heart failure [67]. Three studies confirmed that fewer barriers (e.g., less fear of addiction and tolerance and a better sense of control) led to better adherence to pain medication [26, $30,31]$. In contrast, two other studies found no correlation between decreases in barriers and pain levels [33, 69]. A further study $(n=342)$ showed that patients' beliefs were not associated with reports about pain or adherence to medication [68]. Interventions should probably have a multifaceted design that not only incorporates education on various disease-related topics, but also implements strategies for changing patient behavior [69].

\section{Limitations}

Our study population knew that they were enrolled in pain research, which may have stimulated both the intervention and the control group to talk about their pain with their treating physicians or other health care providers and diminished the distinction between the two groups. Another factor that might have affected comparability between the intervention and control groups is the severe illness in the patient population and the inherent inability to control disease progression.

Written communication with the treating physicians proved to be inadequate. Future research should include a more direct means of communication.

\section{Recommendations}

We recommend that researchers consider the following components in future education programs due to their potential ability to reduce pain levels in the longer-term: (1) Involve the patient and family caregivers as much as possible [31, 42]. (2) Communicate with the patient by 
telephone to reinforce the information and to monitor pain $[27,31,42]$. (3) Integrate medical care into the nursingbased education program, i.e., direct contact between the nurse and the physician who can adjust the analgesic regimen. (4) Formulate clear instructions as to how and when to contact the doctor [34]. (5) Have the patients keep a pain diary and let them refer to it during communication with their health care providers [34].

Further research is needed to test the efficacy of the separate components and to establish the most effective intensity of PEPs. In order to investigate the exact mechanism of how pain levels can be reduced in the longer-term, we recommend that studies measure not only knowledge, pain, symptoms, and quality of life, but also the pain medication regimen [34], medication adherence (e.g., by using a pillbox) [31], and communication between the patients and their physicians.

\section{Conclusions}

This study showed that a PEP presented by nurses could lower pain intensity in cancer patients. Patients with higher pain scores benefited more from the intervention, and the effects lasted longer.

Our results support those of earlier studies in which nurses gave pain education to patients and increased their knowledge of pain. However, no correlation was found between an increase in pain knowledge and a decrease in pain level. As well as educating patients, more attention should be paid to the communication between patients and professional care providers on pain and pain management.

Acknowledgement We are grateful to Eliane Perree and Paul Oyen, the nurses who presented the PEP to the patients.

Open Access This article is distributed under the terms of the Creative Commons Attribution Noncommercial License which permits any noncommercial use, distribution, and reproduction in any medium, provided the original author(s) and source are credited.

\section{References}

1. van den Beuken-van Everdingen M, Rijke de J, Kessels A, Schouten H, Kleef van M, Patijn J (2007) Prevalence of pain in patients with cancer: a systematic review of the past 40 years. Ann Oncol 18(9):1437-1449. doi:10.1093/annonc/ mdm056

2. Fazeny B, Muhm M, Hauser I et al (2000) Barriers in cancer pain management. Wien Klin Wochenschr 112(22):978-981

3. Patrick DL, Ferketich SL, Frame PS et al (2004) National Institutes of Health State-of-the-Science Conference Statement: symptom management in cancer: pain, depression, and fatigue, July 15-17, 2002. J Natl Cancer Inst Monogr(32):9-16
4. Von Roenn JH, Cleeland CS, Gonin R, Hatfield AK, Pandya KJ (1993) Physician attitudes and practice in cancer pain management. A survey from the Eastern Cooperative Oncology Group. Ann Intern Med 119(2):121-126

5. Hill CS Jr (1993) The barriers to adequate pain management with opioid analgesics. Semin Oncol 20(2):1-5

6. Ward SE, Goldberg N, Miller-McCauley V et al (1993) Patientrelated barriers to management of cancer pain. Pain 52(3):319324. doi:10.1016/0304-3959(93)90165-L

7. Kissane DW, Grabsch B, Love A, Clarke DM, Bloch S, Smith GC (2004) Psychiatric disorder in women with early stage and advanced breast cancer: a comparative analysis. Aust N Z J Psychiatry 38(5):320-326. doi:10.1111/j.1440-1614. 2004.01358.x

8. Ferrell BR, McCaffery M, Rhiner M (1992) Pain and addiction: an urgent need for change in nursing education. J Pain Symptom Manage 7(2):117-124. doi:10.1016/0885-3924(92)90123-Y

9. Taylor EJ, Ferrell BR, Grant M, Cheyney L (1993) Managing cancer pain at home: the decisions and ethical conflicts of patients, family caregivers, and homecare nurses. Oncol Nurs Forum 20(6):919-927

10. Yun YH, Heo D et al (2003) Multicenter study of pain and its management in patients with advanced cancer in Korea. J Pain Symptom Manage 25(5):430-437

11. Shvartzman P, Friger M, Shani A et al (2003) Pain control in ambulatory cancer patients - can we do better. J Pain Symptom Manage 26(2):716-722. doi:10.1016/S0885-3924(03) 00220-3

12. Du Pen SL, Du Pen AR, Polissar N et al (1999) Implementing guidelines for cancer pain management: results of a randomized controlled clinical trial. J Clin Oncol 17(1):361-370

13. Riddell A, Fitch MI (1997) Patients' knowledge of and attitudes toward the management of cancer pain. Oncol Nurs Forum 24 (10): $1775-1784$

14. Miaskowskin C, Dodd MJ, West C et al (2001) Lack of adherence with the analgesic regimen: a significant barrier to effective cancer pain management. J Clin Oncol 19(23):4275-4279

15. Johnson DC, Kassner CT, Houser J, Kutner JS (2005) Barriers to effective symptom management in hospice. J Pain Symptom Manage 29(1):69-79. doi:10.1016/j.jpainsymman.2004. 09.001

16. Lin CC (2000) Barriers to the analgesic management of cancer pain: a comparison of attitudes of Taiwanese patients and their family caregivers. Pain 88(1):7-14. doi:10.1016/S0304-3959(00) 00303-1

17. Liang LP, Dunn SM, Gorman A, Stuart-Harris R (1990) Identifying priorities of psychosocial need in cancer patients. $\mathrm{Br}$ J Cancer 62(6):1000-1003

18. Snyder CF, Dy SM, Hendricks DE et al (2007) Asking the right questions: investigating needs assessments and health-related quality-of-life questionnaires for use in oncology clinical practice. Support Care Cancer 15(9):1075-1085. doi:10.1007/s00520-0070223-1

19. Bender JL, Hohenadel J, Wong J et al (2007) What patients with cancer want to know about pain: qualitative study. J Pain Symptom Manage 35:177-187

20. Goldberg GR, Morrison RS (2007) Pain management in hospitalized cancer patients: a systematic review. J Clin Oncol 25 (13):1792-1801. doi:10.1200/JCO.2006.07.9038

21. Camp-Sorrell D, O'Sullivan P (1991) Effects of continuing education. Pain assessment and documentation. Cancer Nurs 14 (1):49-54. doi:10.1097/00002820-199102000-00008

22. Kravitz RL, Delafield JP, Hays RD, Drazin R, Conolly M (1996) Bedside charting of pain levels in hospitalized patients with cancer: a randomized controlled trial. J Pain Symptom Manage 11 (2):81-87. doi:10.1016/0885-3924(95)00155-7 
23. Morrison RS, Meier DE, Fischberg D et al (2006) Improving the management of pain in hospitalized adults. Arch Intern Med 166 (9):1033-1039. doi:10.1001/archinte.166.9.1033

24. Anderson KO, Mendoza TR, Payne R et al (2004) Pain education for underserved minority cancer patients: a randomized controlled trial. J Clin Oncol 22(24):4918-4925. doi:10.1200/JCO. 2004.06.115

25. Aubin M, Vezina L, Parent $\mathrm{R}$ et al (2006) Impact of an educational program on pain management in patients with cancer living at home. Oncol Nurs Forum 33(6):1183-1188. doi:10.1188/ 06.ONF.1183-1188

26. Chang MC, Chang YC, Chiou JF, Tsou TS, Lin CC (2002) Overcoming patient-related barriers to cancer pain management for home care patients. A pilot study. Cancer Nurs 25(6):470-476. doi:10.1097/00002820-200212000-00012

27. Given B, Given CW, McCorkle R et al (2002) Pain and fatigue management: results of a nursing randomized clinical trial. Oncol Nurs Forum 29(6):949-956. doi:10.1188/02.ONF.949-956

28. Keefe FJ, Ahles TA, Sutton L et al (2005) Partner-guided cancer pain management at the end of life: a preliminary study. J Pain Symptom Manage 29(3):263-272. doi:10.1016/j.jpainsymman. 2004.06.014

29. Lai YH, Guo SL, Keefe FJ et al (2004) Effects of brief pain education on hospitalized cancer patients with moderate to severe pain. Support Care Cancer 12(9):645-652

30. Lin CC, Chou PL, Wu SL, Chang YC, Lai YL (2006) Long-term effectiveness of a patient and family pain education program on overcoming barriers to management of cancer pain. Pain 122 (3):271-281. doi:10.1016/j.pain.2006.01.039

31. Miaskowski C, Dodd M, West C et al (2004) Randomized clinical trial of the effectiveness of a self-care intervention to improve cancer pain management. J Clin Oncol 22(9):1713-1720. doi:10.1200/JCO.2004.06.140

32. Rimer B, Levy MH, Keintz MK, Fox L, Engstrom PF, MacElwee N (1987) Enhancing cancer pain control regimens through patient education. Patient Educ Couns 10(3):267-277. doi:10.1016/07383991(87)90128-5

33. Syrjala KL, Abrams JR, Polissar NL et al (2007) Patient training in cancer pain management using integrated print and video materials: a multisite randomized controlled trial. Pain 135:175186

34. Vallieres I, Aubin M, Blondeau L, Simard S, Giguere A (2006) Effectiveness of a clinical intervention in improving pain control in outpatients with cancer treated by radiation therapy. Int J Radiat Oncol Biol Phys 66(1):234-237. doi:10.1016/j. ijrobp.2005.12.057

35. Ward S, Donovan HS, Owen B, Grosen E, Serlin R (2000) An individualized intervention to overcome patient-related barriers to pain management in women with gynecologic cancers. Res Nurs Health 23(5):393-405. doi:10.1002/1098-240X(200010) 23:5<393::AID-NUR6>3.0.CO;2-O

36. Wells N, Hepworth JT, Murphy BA, Wujcik D, Johnson R (2003) Improving cancer pain management through patient and family education. J Pain Symptom Manage 25(4):344-356. doi:10.1016/ S0885-3924(02)00685-1

37. Wit de R, Dam van F, Zandbelt L et al (1997) A pain education program for chronic cancer pain patients: follow-up results from a randomized controlled trial. Pain 73(1):55-69. doi:10.1016/ S0304-3959(97)00070-5

38. Oliver JW, Kravitz RL, Kaplan SH, Meyers FJ (2001) Individualized patient education and coaching to improve pain control among cancer outpatients. J Clin Oncol 19(8):22062212

39. Yates P, Edwards H, Nash R et al (2004) A randomized controlled trial of a nurse-administered educational intervention for improving cancer pain management in ambulatory settings.
Patient Educ Couns 53(2):227-237. doi:10.1016/S0738-3991 (03)00165-4

40. Clotfelter CE (1999) The effect of an educational intervention on decreasing pain intensity in elderly people with cancer. Oncol Nurs Forum 26(1):27-33

41. Schumacher KL, West C, Dodd M et al (2002) Pain management autobiographies and reluctance to use opioids for cancer pain management. Cancer Nurs 25(2):125-133. doi:10.1097/ 00002820-200204000-00009

42. Wit de R, Dam van F, Loonstra S et al (2001) Improving the quality of pain treatment by a tailored pain education programme for cancer patients in chronic pain. Eur J Pain 5(3):241-256. doi:10.1053/eujp.2001.0239

43. de Wit R, van Dam F, Vielvoye-Kerkmeer A, Mattern C, AbuSaad HH (1999) The treatment of chronic cancer pain in a cancer hospital in The Netherlands. J Pain Symptom Manage 17(5):333350. doi:10.1016/S0885-3924(98)00150-X

44. Reyes-Gibby CC, Aday LA, Anderson KO, Mendoza TR, Cleeland CS (2006) Pain, depression, and fatigue in community-dwelling adults with and without a history of cancer. J Pain Symptom Manage 32(2):118-128. doi:10.1016/j.jpainsymman.2006.01.008

45. Pasquini M, Biondi M (2007) Depression in cancer patients: a critical review. Clin Pract Epidemol Ment Health 3:2. doi:10.1186/ 1745-0179-3-2

46. Zandbelt LC Pijn bij kanker en wat er aan te doen is. De ontwikkeling en pretest van een brochure over pijn en pijnbestrijding voor kankerpatiënten met langdurige pijn. Doctoraalscriptie. Rijksuniversiteit Limburg (1993)

47. Daut RL, Cleeland CS Flanery RC (1983) Development of the Wisconsin Brief Pain Questionnaire to assess pain in cancer and other diseases. Pain 17(2):197-210. doi:10.1016/0304-3959(83) 90143-4

48. Serlin RC, Mendoza TR, Nakamura Y, Edwards KR, Cleeland CS (1995) When is cancer pain mild, moderate or severe? Grading pain severity by its interference with function. Pain 61(2):277284. doi:10.1016/0304-3959(94)00178-H

49. Caraceni A, Mendoza TR, Mencaglia E et al (1996) A validation study of an Italian version of the Brief Pain Inventory (Breve Questionario per la Valutazione del Dolore). Pain 65(1):87-92. doi:10.1016/0304-3959(95)00156-5

50. Wang XS, Mendoza TR, Gao SZ, Cleeland CS (1996) The Chinese version of the Brief Pain Inventory (BPI-C): its development and use in a study of cancer pain. Pain 67(23):407-416. doi:10.1016/0304-3959(96)03147-8

51. Uki J, Mendoza T, Cleeland CS, Nakamura Y, Takeda F (1998) A brief cancer pain assessment tool in Japanese: the utility of the Japanese Brief Pain Inventory-BPI-J. J Pain Symptom Manage 16(6):364-373. doi:10.1016/S0885-3924(98)00098-0

52. Ger LP, Ho ST, Sun WZ, Wang MS, Cleeland CS (1999) Validation of the Brief Pain Inventory in a Taiwanese population. J Pain Symptom Manage 18(5):316-322. doi:10.1016/S08853924(99)00087-1

53. Radbruch L, Loick G, Kiencke P et al (1999) Validation of the German version of the Brief Pain Inventory. J Pain Symptom Manage 18(3):180-187. doi:10.1016/S0885-3924(99)00064-0

54. Radbruch L, Sabatowski R, Elsner F, Everts J, Mendoza T, Cleeland C (2003) Validation of the German version of the brief fatigue inventory. J Pain Symptom Manage 25(5):449-458. doi:10.1016/S0885-3924(03)00073-3

55. Saxena A, Mendoza T, Cleeland CS (1999) The assessment of cancer pain in north India: the validation of the Hindi Brief Pain Inventory-BPI-H. J Pain Symptom Manage 17(1):27-41. doi:10.1016/S0885-3924(98)00104-3

56. Mystakidou K, Mendoza T, Tsilika E et al (2001) Greek brief pain inventory: validation and utility in cancer pain. Oncology 60 (1):35-42. doi:10.1159/000055294 
57. Larue F, Colleau SM, Brasseur L, Cleeland CS (1995) Multicentre study of cancer pain and its treatment in France. BMJ 310 (6986): 1034-1037

58. Stone AA, Broderick JE, Shiffman SS, Schwartz JE (2004) Understanding recall of weekly pain from a momentary assessment perspective: absolute agreement, between- and withinperson consistency, and judged change in weekly pain. Pain 107 (1-2):61-69. doi:10.1016/j.pain.2003.09.020

59. Ferrell BR, Rhiner MR, Rivera LM (1993b) Development and evaluation of the family pain questionnaire. J Psychosoc Oncol 10:21-35. doi:10.1300/J077V10N04_02

60. Ferrell BR, Ferrell BA, Ahn C, Tran K (1994) Pain management for elderly patients with cancer at home. Cancer 74(7):2139-2146. doi:10.1002/1097-0142(19941001)74:7 +<2139::AIDCNCR2820741722>3.0.CO;2-C

61. Aaronson NK, Ahmedzai S, Bergman B et al (1993) The European Organization for Research and Treatment of Cancer QLQ-C30: a quality-of-life instrument for use in international clinical trials in oncology. J Natl Cancer Inst 85(5):365-376. doi:10.1093/jnci/85.5.365

62. Zigmond AS, Snaith RP (1983) The hospital anxiety and depression scale. Acta Psychiatr Scand 67(6):361-370. doi:10.1111/j.1600-0447.1983.tb09716.x

63. Bjelland I, Dahl AA, Haug TT, Neckelmann D (2002) The validity of the Hospital Anxiety and Depression Scale. An updated literature review. J Psychosom Res 52(2):69-77. doi:10.1016/S0022-3999(01)00296-3

64. Blackwell E, de Leon CF, Miller GE (2006) Applying mixed regression models to the analysis of repeated-measures data in psychosomatic medicine. Psychosom Med 68(6):870-878. doi:10.1097/01.psy.0000239144.91689.ca

65. Vissers KCP (2007) (Nederlandse Vereniging voor Anesthesie). Richtlijn diagnostiek en behandeling van pijn bij patiënten met kanker

66. Grover SA, Lowensteyn IL, Joseph L et al (2007) Patient knowledge of coronary risk profile improves the effectiveness of dyslipidemia therapy. Arch Intern Med 167(21):2296-2303. doi:10.1001/archinte.167.21.2296

67. Krumholz HM, Amatruda J, Smith GL et al (2002) Randomized trial of an education and support intervention to prevent readmission of patients with heart failure. J Am Coll Cardiol 39 (1):83-89. doi:10.1016/S0735-1097(01)01699-0

68. Dawson R, Sellers DE, Spross JA, Jablonski ES, Hoyer DR, Solomon MZ (2005) Do patient's beliefs act as barriers to effective pain management behaviors and outcomes in patients with cancer-related or noncancer-related pain. Oncol Nurs Forum 32(2):363-374. doi:10.1188/05.ONF.363-374

69. Bourbeau J, Nault D, Dang-Tan T (2004) Self-management and behaviour modification in COPD. Patient Educ Couns 52(3):271277. doi:10.1016/S0738-3991(03)00102-2 